\title{
Outcomes of 23-gauge pars plana vitrectomy in vitreoretinal diseases
}

\author{
Betül IIlkay Sezgin Akçay' \\ Osman Murat Uyar ${ }^{2}$ \\ Fevzi Akkan² \\ Kadir Eltutar ${ }^{2}$ \\ 'Ümraniye Training and Research \\ Hospital, İstanbul, Turkey; ${ }^{2}$ istanbul \\ Training and Research Hospital, \\ Istanbul, Turkey
}

This article was published in the following Dove Press journal:

Clinical Ophthalmology

I3 December 201।

Number of times this article has been viewed
Purpose: The aim of this study was to assess the efficiency and reliability of the 23-gauge $(23 \mathrm{G})$ transconjunctival vitrectomy system and examine possible complications of this surgical technique in a variety of vitreoretinal conditions along with early postoperative intraocular pressure (IOP) changes.

Materials and methods: $A$ total of 350 eyes of 324 patients having undergone $23 \mathrm{G}$ transconjunctival vitrectomy were included in this prospective study. A total of $150(46.2 \%)$ were male and 174 (53.8\%) female, with a mean age of $61.28 \pm 15.67$ years. Mean follow-up time was 8.3 months. Results: Mean BCVA logMARs were as follows: preoperatively $0.839 \pm 0.59$, postoperatively first day $2.07 \pm 0.76$, first week $1.14 \pm 0,43$, first month $0.63 \pm 0.26$ and last examination $0.359 \pm$ 0.17 . Mean BCVA decreased significantly $(P<0.001, P<0.028$, respectively) on postoperative first day and first week, mainly due to air or gas tamponade, and increased significantly in the first month and final control in almost all indications $(P<0.001)$. Postoperative mild hypotony (IOP $\leq 10 \mathrm{mmHg}$ ) was detected in $112(32 \%)$ eyes on day 1 and in $59(16.8 \%)$ eyes in week 1 . While postoperative serious hypotony $(\leq 5 \mathrm{mmHg}$ ) was detected in $34(9.7 \%)$ eyes on day 1 , it was not detected in any eyes at the end of the first week. None of the eyes required an additional gas tamponade or any other procedure in the early postoperative period due to hypotony. A total of $13(3.7 \%)$ eyes were reoperated for recurrent vitreous hemorrhage; $23(6.5 \%)$ eyes were reoperated on a second time, nine $(2.5 \%)$ a third time, and $1(0.2 \%)$ a fourth time for recurrent rhegmatogenous retinal detachment. Postoperative fibrinoid reaction was seen in 17 (4.8\%) eyes on the first day and responded well to the medications. Cataract development was found in 61 $(22.5 \%)$ of the 270 phakic eyes after a mean duration of $6.4 \pm 3.5$ months. Anatomical success was obtained in $86 \%$ of the patients and functional success in $72 \%$.

Conclusion: The $23 \mathrm{G}$ transconjunctival vitrectomy system is safe and effective in a wide field of vitreoretinal conditions. It is a good alternative to $20 \mathrm{G}$ and $25 \mathrm{G}$ techniques but needs some improvement mainly in regards to the instruments and related techniques; further larger controlled group studies are needed.

Keywords: vitreoretinal surgery, $23 \mathrm{G}$ transconjunctival vitrectomy

\section{Introduction}

Technological advancements in vitreoretinal surgery have made it possible to surgically treat certain diseases which had been considered hard for a long time. Invented by Machemer in the early 1970s, the "pars plana vitrectomy" technique has led to an increasingly more advanced and promising treatment, which calls for limited intervention. Introduced for the first time by Claus Eckardt, the 23-gauge $(23 \mathrm{G})$ transconjunctival vitrectomy technique is commonly accepted by vitreoretinal surgeons in daily practice. In this study, the outcomes of 350 cases of $23 \mathrm{G}$ pars plana vitrectomies
Correspondence: Betül illkay Sezgin Akçay Acıbadem Caddesi Hukukçular Sitesi, A blok, No 8 istanbul, Turkey

$\mathrm{Tel}+902163258219$

Fax +90 2166327I24

Email betul_sezgin@yahoo.com submit your manuscript | www.dovepress.com

Dovepress

http://dx.doi.org// 0.2147/OPTH.S23910 which permits unrestricted noncommercial use, provided the original work is properly cited. 
with different etiologies performed at the İstanbul Training and Research Hospital, Ophthalmology Clinic were assessed. The aim was to assess the efficiency and reliability of the $23 \mathrm{G}$ transconjunctival vitrectomy system and examine possible complications of this surgical technique along with early postoperative intraocular pressure (IOP) changes.

\section{Materials and methods}

Between November 2005 and December 2007, 23G transconjunctival vitrectomy was performed in the clinic on 350 eyes of 324 patients. In this prospective study, all 350 eyes of these 150 male (46.2\%) and 174 female (53.8\%) patients were examined. Mean follow-up time was 8.3 months (4-48 months). Mean age was $61.28 \pm 15.67$ years. Informed consent according to the Declaration of Helsinki were taken prior to surgery. The vitrectomy indications in the study are indicated in Table 1.

Best-corrected visual acuity (BCVA) was measured using the ETDRS (Early Treatment Diabetic Retinopathy Study) and Snellen charts. For ease of analysis, visual acuity was turned into $\log$ MAR (logarithm of the minimum angle of resolution) scores. IOP measurements were made with Goldmann applanation tonometry. IOP $\leq 10 \mathrm{mmHg}$ was considered as mild hypotony and $\leq 5 \mathrm{mmHg}$ as serious hypotony. Biomicroscopic findings regarding the cornea, conjunctiva, and anterior chamber were noted. The funduscopic examination was carried out by contact lenses and binocular indirect ophthalmoscope. In cases where fundus imaging was not possible, mode A and B ultrasonographic examination was undertaken. In this series, B-mode ultrasonographic examination was undertaken on all eyes with vitreous hemorrhage (VH) in the preoperative period. All patients with vitreomacular surface disorders were examined with the Stratus OCT ${ }^{\mathrm{TM}}$ III (Carl Zeiss Meditec Inc, Dublin, CA) device. Intraoperative or postoperative complications such as leakage from sclerotomy, hemorrhage, vitreous or retinal incarceration, retinal detachment at transconjunctival

Table I 23 Gauge vitrectomy indications

\begin{tabular}{lll}
\hline & (n) & (\%) \\
\hline Retinal detachment (RRD) & 98 & 28 \\
Intravitreal hemorrhage (IVH) & 80 & 22.8 \\
Proliferative diabetic retinopathy and membranes (DTRD) & 62 & 17.7 \\
Idiopathic and secondary epiretinal membranes (ERM) & 54 & 15.4 \\
Macular hole (MH) & 27 & 7.7 \\
Vitreomacular traction (VMT) & 8 & 2.2 \\
Endophthalmitis & 7 & 2 \\
Dislocations of the lens particles to vitreous & 7 & 2 \\
Vitreous opacities & 7 & 2 \\
\hline
\end{tabular}

entry, or dialysis were noted. Goldmann three-mirror and extreme wide field contact lenses were used to evaluate the vitreous base.

Retinal detachment, vitreous or suprachoroidal hemorrhage, choroidal detachment or folds, and endophthalmitis incidence was assessed. Anti-vascular endothelial growth factor was injected into some diabetic $\mathrm{VH}$ and diabetic tractional retinal detachment (DTRD) cases 2-7 days before surgery, and in one case at the beginning only of the operation.

The operations were performed under local or general anesthesia. Sclerotomies were performed from upper temporal, lower temporal, and upper nasal quadrants, 3.0, 3.5 , and $4.0 \mathrm{~mm}$ from the corneoscleral limbus in aphakic, pseudophakic, and phakic cases, respectively, by using a $23 \mathrm{G}$ microvitreoretinal knife parallel to the limbus and at an angle. In order to prevent postoperative leakage, the scleral tunnel that formed in the sclerotomy with this technique was moved slightly to the conjunctiva with the help of a special fixation technique known as conjunctival fixation (Figure 1). The first microcannula was inserted in the lower temporal sclerotomy, followed by infusion. Balanced saline solution was used as the infusion fluid (Figure 2). Air, expansile gas, or silicone oil (1000 centistokes, 5000 centistokes) was used as endotamponade when necessary; hexafluoride (SF6) was used in $60(17.1 \%)$ eyes, perfluoropropane (C3F8) in 105 (30\%) eyes, silicone oil in 65 (18.7\%) eyes, and air in 74 (21.1\%) eyes; 46 (13.1\%) eyes were left with fluid. Silicone oil was injected after the fluid-air or fluid PFC - silicone exchange in some of the cases, without enlarging the sclerotomies.

Peripheral iridectomy at the 6 o'clock position was performed in aphakic eyes before silicone oil tamponade. Any sclerotomy leaking air, gas, liquid, or especially silicone oil was sutured with $7 / 0$ vicryl at the end of surgery.

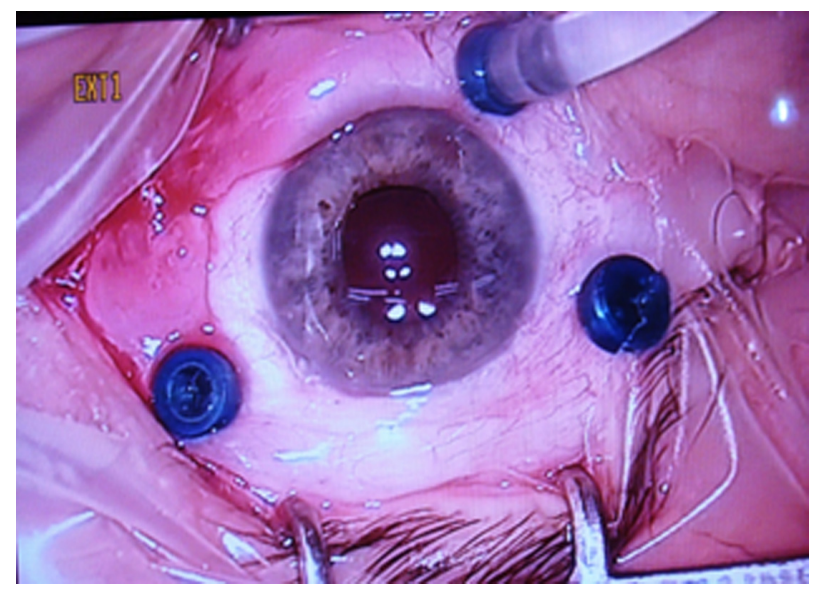

Figure I Trocar and infusion canula positions in 23 gauge vitrectomy. 


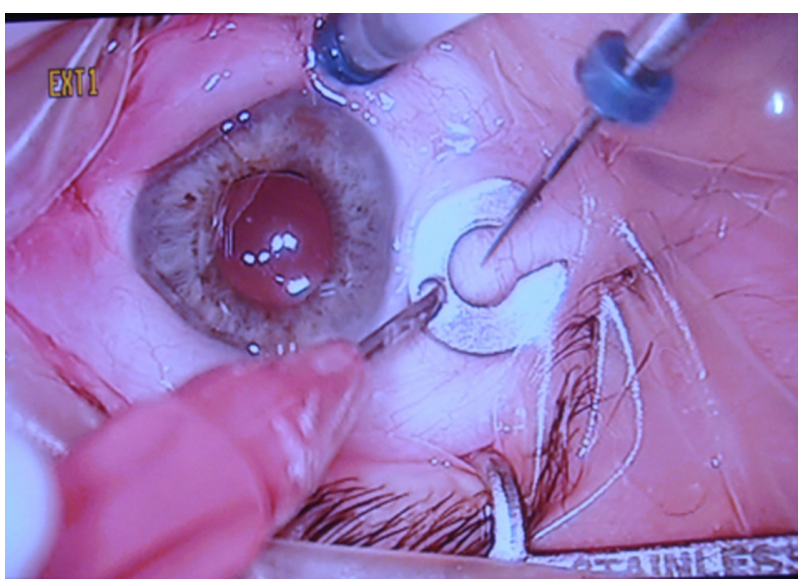

Figure 2 Specially designed pressure plate for holding the conjunctiva.

Subconjunctival antibiotics and steroid injections were administered at the end of surgery. Statistical analyses were done by using SPSS Statistics (IBM Corporation, Somers, NY) software, version 11.5 for Windows. The difference between pre- and postoperative visual acuity and IOP levels were compared by using two-tailed paired $t$-test. Results with a $P$-value below 0.05 were considered statistically significant.

\section{Results}

Mean BCVA logMARs were as follows: preoperatively 0.839 \pm 0.59 , postoperatively first day $2.07 \pm 0.76$, first week 1.14 $\pm 0,43$, first month $0.63 \pm 0.26$ and last examination $0.359 \pm$ 0.17 . Mean BCVA decreased significantly $(P<0.001, P<$ 0.028 , respectively) on postoperative first day and first week, mainly due to air or gas tamponade, and increased significantly in the first month and final control $(P<0.001)$.

Preoperative BCVA logMARs were $0.658(3.10-0)$ in RRD, 1.155 (3.10-0.4) in IVH, 1.046 (3.10-0.4) in DTRD,
$0.495(1.0-0.22)$ in ERM, $0.796(1.10-0.3)$ in $\mathrm{MH}, 0.538$ (1.10-0.15) in VMT, 1.699 (3.10-0.4) in endophtalmitis, $0.620(3.10-0)$ in dislocations of the lens particles, 0.456 $(1.0-0.3)$ in vitreous opacities.

Postoperative final BCVA logMARs were 0.337 (3.10-0) in RRD, 0.276 (3.10-0) in IVH, $0.620(3.10-1.125)$ in DTRD, 0.237(1.0-0) in ERM, 0.420 (1.10-0.3) in MH, 0.222 (1.10-0.15) in VMT, 0.658 (3.10-0.22) in endophtalmitis, $0.108(3.10-0)$ in dislocations of the lens particles and 0.143 $(1.0-0.05)$ in vitreous opacities (Table 2).

Mean intraocular pressure values for all patients prior to the operation was $14.75 \pm 7.1$, followed by the postoperative day 1 value of $11.62 \pm 9.7(P<0.001)$, postoperative week 1 value of $15.86 \pm 6.6(P=0.330)$, and postoperative month 1 value of $16.84 \pm 5.6(P=0.556)$. Last postoperative mean intraocular pressure was $15.1 \pm 3.9(P=0.306)$.

Postoperative mild hypotony (IOP $\leq 10 \mathrm{mmHg}$ ) was detected in $112(32 \%)$ eyes on day 1 and in $59(16.8 \%)$ eyes in week 1 . While postoperative serious hypotony $(\leq 5 \mathrm{mmHg})$ was detected in 34 (9.7\%) eyes on day 1, it was not detected in any eyes at the end of the first week. None of the eyes required an additional gas tamponade or any other procedure in the early postoperative period due to hypotony. During the follow-up, no choroidal effusion, detachment, or folds developed, and no vitreous incarceration around the wound was noted. Single sclerotomies of four patients who had nucleus fragments in the vitreous cavity were changed to $20 \mathrm{G}$ for phacofragmentation, as a $23 \mathrm{G}$ phacofragmentation probe was not available at that time. In all macular hole $(\mathrm{MH})$ cases (stages 2-4), internal limiting membrane peeling and fluid/air/gas exchange were performed. Postoperative optical coherence tomography (OCT) revealed opening of the $\mathrm{MH}$ in five (18.1\%) eyes after a mean duration of $3.73 \pm 2.92$ months.

Table 2 Mean preoperative and postoperative visual acuities

\begin{tabular}{|c|c|c|c|c|}
\hline & $\mathbf{N}(\%)$ & $\begin{array}{l}\text { Preoperative VA } \\
\text { (logMAR) }\end{array}$ & $\begin{array}{l}\text { Postoperative VA final } \\
\text { (logMAR) }\end{array}$ & $P$ \\
\hline RRD & $98(28)$ & 0.658 & 0.337 & $<0.001$ \\
\hline IVH & $80(22.9)$ & I.I55 & 0.276 & $<0.001$ \\
\hline DTRD & $62(17.7)$ & 1.046 & 0.620 & $<0.001$ \\
\hline ERM & $54(15.4)$ & 0.495 & 0.237 & $<0.001$ \\
\hline $\mathrm{MH}$ & $27(7.7)$ & 0.796 & 0.420 & $<0.001$ \\
\hline VMT & $8(2.3)$ & 0.538 & 0.222 & $\neq$ \\
\hline Endophthalmitis & $7(2)$ & 1.699 & 0.658 & $\ddagger$ \\
\hline Dislocations of the lens particles to vitreous & $7(2)$ & 0.620 & 0.108 & $\ddagger$ \\
\hline Vitreous opacities & $7(2)$ & 0.456 & 0.143 & $\neq$ \\
\hline
\end{tabular}

Notes: $\ddagger$ Low number of patients.

Abbreviations: VA, visual acuity; RRD, rhegmatogenous retinal detachment; IVH, intravitreal hemorrhage; DTRD, diabetic tractional retinal detachment; ERM, epiretinal membrane; $\mathrm{MH}$, macular hole; VMT, vitreomacular traction. 
Holes of four were closed after the second $23 \mathrm{G}$ pars plana vitrectomy. All grades of retinal detachments were submitted to $23 \mathrm{G}$ pars plana vitrectomy. Advanced proliferative vitreoretinopathy cases had combined lens surgery, radial retinotomies of up to $360^{\circ}$, retinectomies, and/or encircling scleral buckles. In some DTRD cases, bimanual surgery was performed.

Among the rhegmatogenous retinal detachment (RRD) patients, 68 were given C3F8 gas and 44 were given silicone oil tamponade in the primary surgery. Of the 98 cases, $23(6.5 \%)$ eyes were reoperated on a second time, nine $(2.5 \%)$ a third time, and one $(0.2 \%)$ a fourth time for recurrent RRD. Encircling scleral buckles were used in 13 (3.5\%) of those cases. In some of the 11 cases (3.1\%) who had silicone leakage either outside and/or under the conjunctiva after the removal of trocars, silicone oil was found inadequate in the vitreous cavity in the postoperative period. It was noted that recurrence was mostly observed in these patients. Anatomical and functional success rates were obtained from the patients' last visit findings. Anatomical success was defined as: reattachment of retinal detachments until the final visit, relieving of tractional detachments of DTRDs, cleaning of VHs, vitreous opacities, and nuclear fragments; closure of MHs; absence of epiretinal membranes (ERMs) and vitreomacular traction syndrome (VMT) confirmed by OCT. On the other hand, functional success was defined as BCVA of Snellen 1/20 (logMAR 1.3) or better on last follow-up and no reduction in visual acuity as compared with the preoperative period.

Functional success, on the other hand, was defined as BCVA of 1/20 or higher on last follow-up and no reduction in vision as compared with the preoperative period. Evaluated according to these success criteria, anatomical success was obtained in $86 \%$ of the patients and functional success in $72 \%$. Revitrectomy was performed in $13(3.7 \%)$ diabetic patients for intravitreous bleed. It was thought that the major reasons were because of mild or serious hypotony and inadequate peripheral vitreous dissection and inadequate peripheral laser photocoagulation, especially in the phakic eyes.

Of the 350 patients, 270 were phakic. On postoperative follow-up, cataract was found in 61 (22.5\%) of the 270 phakic eyes after a mean duration of $6.4 \pm 3.5$ months. Of these patients, 52 underwent phacoemulsification and intraocular lens implantation, and nine were left aphakic. Sclerotomy had to be shifted to $20 \mathrm{G}$ for comfortable tool manipulation in four eyes that had lens fragmentation in the vitreous. Fibrin reaction was observed in the anterior chamber of 17 (4.8\%) eyes on the first postoperative day. These all had resolution by pupillary dilatation, steroid treatment, and fortified antibiotic eyedrops during the follow-up.

\section{Discussion}

The 20G vitrectomy technique has been a widely accepted technique by surgeons for more than 20 years. It is quite effective in cleaning thick hemorrhages, and fibrous bands and has large clinical application potential. However, transconjunctival techniques are starting to be preferred due to shorter operation time, less need of suturing, less postoperative inflammation, and less pain.

Developed recently by Fujii et al, ${ }^{5}$ the transconjunctival unsutured vitrectomy technique is one of the most important advances of vitreoretinal surgery. Owing to the thinness of $25 \mathrm{G}$ instruments, sclera recovery can be achieved without needing sutures. Therefore, suture-related astigmatism and discomfort can be eliminated. As is widely known, sutures used without covering the sclerotomy area cause irritation and pigmentation in the sclerotomy area. Thirty-two percent local inflammatory reaction is reported with Dacron and 5\% with polyglycolic acid. With unsutured surgery, suture-related irritation and local inflammatory reaction can be prevented. Various previous studies have stated that unsutured smallincision cataract surgery reduces postoperative inflammatory reaction. ${ }^{1-3}$ Karaçorlu et al compared 14 unsutured eyes and 20 sutured eyes after applying $20 \mathrm{G}$ pars plana vitrectomy. While the eight patients who were sutured displayed ocular surface irritation and one eye displayed scleral pigmentation, these complications were not seen in any of the unsutured eyes. ${ }^{4}$ It is believed that, when compared with conventional pars plana vitrectomy, $25 \mathrm{G}$ unsutured vitrectomy causes less postoperative inflammation and faster postoperative recovery. ${ }^{5,6}$ Rizzo et al compared $25 \mathrm{G}$ unsutured vitrectomy and $20 \mathrm{G}$ pars plana vitrectomy in ERM cases and concluded that $25 \mathrm{G}$ unsutured vitrectomy caused less postoperative inflammatory reaction and thus allowed faster rehabilitation. ${ }^{7}$ In addition, discomfort levels in $25 \mathrm{G}$ unsutured vitrectomy patients were also lower. Romero et al compared $25 \mathrm{G}$ unsutured vitrectomy and standard $20 \mathrm{G}$ vitrectomy with respect to inflammation and surgery durations and found that $25 \mathrm{G}$ unsutured vitrectomy took less time and led to less inflammation after the surgery. ${ }^{8}$ Likewise, Chen showed that $25 \mathrm{G}$ unsutured vitrectomy could be performed in a shorter time and led to less inflammation in the postoperative stage. ${ }^{9}$

Vitreous base cleansing takes less time when compared with $25 \mathrm{G}$, and silicone oil injection is faster. In their 13 disease $25 \mathrm{G}$ silicone intake series, Kapran and Acar found the mean silicone oil injection time to be $7.27 \pm 0.48$ minutes, did not 
experience any complications during surgery, and did not need additional sutures. ${ }^{10}$ Although $25 \mathrm{G}$ has thinner calibration, $23 \mathrm{G}$ causes less postoperative hypotony, as oblique entry to the sclera is used. The $23 \mathrm{G}$ vitrectomy technique also has some disadvantages, with postoperative temporary hypotony being the most serious one. However, its rate is lower than for $25 \mathrm{G}$. While Kusuhara et al found a postoperative hypotony rate of $1.5 \%$ following $23 \mathrm{G}$ vitrectomy in 314 eyes, they found a rate of $18.4 \%$ after $25 \mathrm{G}$ vitrectomy. ${ }^{11}$ Also, shifting to $20 \mathrm{G}$ may be necessary in lens dislocations in the vitreous or in certain complicated cases such as intense fibrovascular membrane. In the present study, the transconjunctival vitrectomy outcomes were examined in 350 eyes of 324 patients with intraventricular hemorrhage, MH,VMT, ERM, DTRD, RRD, dislocation of lens fragments in the vitreous, and intravitreal opacity. Lakhanpal et al recorded the total surgery durations of their series of 140 eyes on which they performed $25 \mathrm{G}$ vitrectomy, along with entry, exit, and vitrectomy times. ${ }^{12}$ They reported shorter total surgery times in $25 \mathrm{G}$ vitrectomy as it does not involve the stages of conjunctival peritomy and opening and suturing of the sclera. In their $23 \mathrm{G}$ vitrectomy series, Fine et al found a mean opening time of 1.7 minutes, mean closing time of $1.3 \mathrm{~min}-$ utes, and mean procedural time of 24.1 minutes. ${ }^{13}$ Lakhanpal et al attributed longer surgery times to the fact that the $25 \mathrm{G}$ technique involves two stages. ${ }^{12}$ Previous studies have reported shorter mean total surgery times with unsutured vitrectomy than in eyes on which $20 \mathrm{G}$ was performed. ${ }^{5,13}$ In the present study, a significant increase in postoperative visual acuity was identified in all patients in general. Considering patient groups, RRD, intraventricular hemorrhage, DTRP, ERM, and MH had a statistically significant increase in visual acuity. Patient groups who were admitted to the study due to endophthalmitis, lens dislocation in the vitreous, or vitreomacular traction were not included in the statistics.

Among patients with gas and air tamponade, mean postoperative visual acuity was lower on day 1 and in week 1 , and BCVA was assessed after tamponade resorption. On postoperative follow-up, together with the resorption of internal gas endotamponade (2-8 weeks), mean visual acuity at month 1 was elevated as compared with the preoperative value, and the elevation continued on last follow-up. Other studies about $23 \mathrm{G}$ vitrectomy also reveal a statistically significant increase in postoperative follow-up visual acuity values when compared with those in the preoperative stage. ${ }^{7,13}$ In the present series, low IOP did not cause choroidal detachment/folds or endophthalmitis. Ibarra et a $1^{14}$ and Yanyali et a ${ }^{15}$ conducted studies using $25 \mathrm{G}$, and both reported a significant decrease in IOP on postoperative day 1 , similar to the findings of the present study. Fine et $\mathrm{al}^{13}$ detected severe hypotony on postoperative day 1 , one of their patients required suturing on the same day and choroidal effusion did not occur in any of their patients. After they started to use $23 \mathrm{G}$ vitrectomy, Eckardt stated that the angle of the incision is more important than its size in preventing postoperative hypotony. ${ }^{16}$ In general, the rate of postoperative hypotony is higher in $25 \mathrm{G}$ series than in $23 \mathrm{G}$ series. Shimada et al found hypotony in $20 \%$ of the eyes in which they used fluid as endotamponade. ${ }^{17}$ Fujii et al reported an IOP value below $10 \mathrm{mmHg}$ in $24 \%$ of 64 unsutured vitrectomy patients. ${ }^{5,6}$ As a result of 63 operations, Shimada et al found postoperative low IOP in $9 \%$ of the eyes that they left with air or gas endotamponade and in $20 \%$ of the eyes that they left with fluid. ${ }^{17}$ In the present study, SF6 was used as endotamponade in 60 (17.1\%) eyes, C3F8 in 105 (30\%) eyes, silicone oil in 65 (18.7\%) eyes, air in $74(21.1 \%)$ eyes, and fluid in $46(13.1 \%)$ eyes. Those that were left with fluid were more hypotonic than gas or air, but a significant difference did not exist between the postoperative hypotony rates of eyes in which different endotamponades were applied. This has led to the conclusion that the scleral incision technique may be more important than the choice of endotamponade type in the prevention of leakage or hypotony. As stated by Fine et al, ${ }^{13}$ Eckardt $^{17}$ and Avc1 and Alyamaç, ${ }^{18}$ the $23 \mathrm{G}$ vitrectomy technique is a more reliable one than $25 \mathrm{G}$ and carries fewer complication risks.

In conclusion, $23 \mathrm{G}$ transconjunctival vitrectomy system is safe and effective in a wide field of vitreoretinal conditions. It is a good alternative to $20 \mathrm{G}$ and $25 \mathrm{G}$ techniques but needs some improvement, mainly in regard to the instruments and related techniques; further larger controlled group studies are needed.

\section{Note}

This study was performed at the Istanbul Training and Research Hospital, Ophthalmology Clinic.

\section{Disclosure}

The authors report no conflicts of interest in this work. Further, no funding or proprietary interests are involved in this study.

\section{References}

1. Sanders DR, Spigelman A, Kraff C, Lagouros P, Goldstick B, Peyman GA. Quantitative assessment of postsurgical breakdown of the blood-aqueous barrier. Arch Ophthalmol. 1983;101(1):131-133.

2. Kaiya T. Observation of blood-aqueous barrier function after posterior chamber intraocular lens implantation. $J$ Cataract Refract Surg. 1990;16:320-324.

3. Oshika T, Yoshimura K, Miyata N. Postsurgical inflammation after phacoemulsification and extracapsular extraction with soft or conventional intraocular lens implantation. $J$ Cataract Refract Surg. 1992;18:356-361. 
4. Karaçorlu M, Özdemir H, Karaçorlu S. Sutureless pars plana vitrectomy. Turkish Ophtalmol J. 2003;33:77-80.

5. Fujii GY, De Juan E Jr, Humayun MS, et al. A new 25-gauge instrument system for transconjunctival sutureless vitrectomy surgery. Ophthalmology. 2002;109:1807-1812; discussion 1813. Erratum in: Ophthalmology. 2003;110:9.

6. Fujii GY, De Juan E Jr, Humayun MS, et al. Initial experience using the transconjunctival sutureless vitrectomy system for vitreoretinal surgery. Ophthalmology. 2002;109:1814-1820.

7. Rizzo S, Genovesi-Ebert F, Murri S, et al. 25-gauge, sutureless vitrectomy and standard 20-gauge pars plana vitrectomy in idiopathic epiretinal membrane surgery: a comparative pilot study. Graefes Arch Clin Exp Ophthalmol. 2006;19:1-8.

8. Romero P, Salvat M, Almena M, Baget M, Méndez I. Experience with 25 -gauge transconjunctival vitrectomy compared to a 20-gauge system. Analysis of 132 cases. J Fr Ophthalmol. 2006;29(9):1025-1032.

9. Chen E. 25-Gauge transconjunctival sutureless vitrectomy. Curr Opin Ophthalmol. 2007;18(3):188-193.

10. Kapran Z,Acar N. Removal of silicone oil with 25-gauge transconjunctival sutureless vitrectomy system. Retina. 2007;27(8):1059-1064.

11. Kusuhara S, Ooto S, Kimura D, et al. Outcomes of 23- and 25-gauge transconjunctival sutureless vitrectomies for idiopathic macular holes. Br J Ophthalmol. Sep 2008;92(9):1261-1264.
12. Lakhanpal RR, Humayun MS, de Juan E Jr, et al. Outcomes of 140 consecutive cases of 25-gauge transconjunctival surgery for posterior segment disease. Ophthalmology. 2005;112:817-824.

13. Fine HF, Iranmanesh R, Iturralde D, Spaide RF. Outcomes of 77 consecutive cases of 23-gauge transconjunctival sutureless vitrectomy for posterior segment disease. Ophthalmology. 2007;114:1197-1200.

14. Ibarra MS, Hermel M, Prenner JL, Hassan TS. Longer-term outcomes of transconjunctival sutureless 25 -gauge vitrectomy. Am J Ophthalmol. 2005;139:831-836.

15. Yanyali A, Celik E, Horozoglu F, Oner S, Nohutcu AF. 25-Gauge transconjunctival sutureless pars plana vitrectomy. Eur J Ophthalmol. 2006;16:141-147

16. Eckardt C. Transconjunctival 23-gauge sutureless vitrectomy. Retina. 2005;25:208-211.

17. Shimada H, Nakashizuka H, Mori R, Mizutani Y. Expanded indications for 25-gauge transconjunctival vitrectomy. Jpn J Ophthalmol. 2005;49:397-401

18. Avcı R, Alyamaç G. 23 G vitrectomy surgery. Ret Vit. 2007;15 special edition:113-116.
Clinical Ophthalmology

\section{Publish your work in this journal}

Clinical Ophthalmology is an international, peer-reviewed journal covering all subspecialties within ophthalmology. Key topics include: Optometry; Visual science; Pharmacology and drug therapy in eye diseases; Basic Sciences; Primary and Secondary eye care; Patient Safety and Quality of Care Improvements. This journal is indexed on

\section{Dovepress}

PubMed Central and CAS, and is the official journal of The Society of Clinical Ophthalmology (SCO). The manuscript management system is completely online and includes a very quick and fair peer-review system, which is all easy to use. Visit http://www.dovepress.com/ testimonials.php to read real quotes from published authors. 